\title{
Antioxidant Activity of Cosmetic Formulations Based on Novel Extracts from Seeds of Brazilian Araucaria angustifolia (Bertoll) Kuntze
}

\author{
Gabriela Sprada Tavares da Mota1,2, Angela Bonjorno Arantes1, Gianni Sacchetti3 \\ Antonella Spagnoletti3 , Paola Ziosi' ${ }^{2}$, Emanuela Scalambra3 ${ }^{3}$ Silvia Vertuani2,3, \\ Stefano Manfredini2,3 \\ ${ }^{1}$ School of Health and Biosciences, Pontifícia Universidade Católica do Paraná, Curitiba, Brasil \\ ${ }^{2}$ Ambrosialab, University of Ferrara, Ferrara, Italy \\ ${ }^{3}$ Department of Life Sciences and Biotechnology, School of Pharmacy and Health Products, University of \\ Ferrara, Ferrara, Italy \\ Email: mv9@unife.it
}

Received 1 March 2014; revised 1 April 2014; accepted 8 April 2014

Copyright $(2014$ by authors and Scientific Research Publishing Inc.

This work is licensed under the Creative Commons Attribution International License (CC BY).

http://creativecommons.org/licenses/by/4.0/

(c) (i) Open Access

\section{Abstract}

The process of oxidation, due to free radicals, is the cause of major concern for human health. In particular damages related to the skin have great relevance; therefore, many antioxidants based products are developed and marketed with the intention to counteract the action of free radicals. The seed of Araucaria angustifolia is a rich source of antioxidants due to the presence of bioflavonoids to counteract free radicals damages. In this study, two extracts, one from the seed external teguments (shell) and the other from the inner seed pulp (endosperm and embryo) were obtained in order to evaluate possible applications to the dermo-cosmetic field. In parallel the following different methods were employed to characterize both the extracts and to determine their antioxidant capacity: HPTLC, ABTS and DPPH, ORAC and PLC. The qualitative analysis showed that both extracts have the antioxidant activity, but the quantitative evaluation revealed a more promising bioactivity from the shell than from the pulp. Therefore, it was evaluated the potential skin application of different cosmetic formulations, based on the presence of seed shell extract (W/0 emulsion, $0 / \mathrm{W}$ emulsion and gel). The best result was achieved with the $\mathrm{W} / 0$ emulsion.

\section{Keywords}

Araucaria angustifolia, Sustainability, Seed Alcoholic Extracts, Antioxidant Activity, 


\section{Introduction}

During the last few years, an increasing amount of evidences have been accumulated on the involvement of free radicals and other oxidative species as major responsible for aging and related degenerative processes, among them, cancer, cataract, brain and cardiovascular diseases [1]-[4].

The skin antioxidant system has an extensive area exposed to the environment to protect and, as a consequence, highly exposed to the exogenous radical attack, which makes the defense system be constantly challenged. Consequently, the cosmetology has a significant role in the prevention and attenuation the cutaneous aging through the study of substances with effective antioxidant activity, to be incorporated on cosmetic products for daily care [5].

Plants are known to be important sources of functional substances. Most of them with antioxidant capacity related to innate defense system of the specie against biological (for e.g. phytopathogens) and physical (for e.g. UV radiation) factors which always causes the generation of free radicals. Moreover, plant species from geographical areas such those Amazonian, are often qualitatively and quantitatively more rich in antioxidant compounds most probably because the important biodiversity which characterizes these regions strongly forced the evolutionary process to diversify the secondary metabolism of the plants.

Different plant extracts, when applied in animal models or in cell culture, are capable of neutralizing the free radical reactivity, and decreasing the cellular injuries. These compounds are the polyphenols, and among them, flavonoids are probably those more known, studied and promising active compounds [6] [7].

The present investigation has been carried out on Araucaria angustifolia, a tree belonging to Araucariaceae family, also commonly known as the Paraná-Pine tree or Brazilian pine (Portuguese: pinheiro-do-paraná or pinheirobrasileiro). Its female strobilus consisting of seeds, "pinhão”, (the edible part of A. angustifolia) and bracts (non-developed seeds), has a long history of use as a food in Southeast of Brazil, like flour in regional dishes or baked. Although the common names in various languages refer to the species as a "pine" because of its similarity with the real Pinus species, it is instead more properly an evergreen tree growing to $40 \mathrm{~m}(130 \mathrm{ft})$ tall and 1 $\mathrm{m}$ (3 ft $3 \mathrm{in}$ ) diameter at breast height. The leaves are thick, tough and scale like, triangular, 3 - 6 centimetres (1.2 - 2.4 in) long, 5 - 10 millimetres (0.2 - 0.4 in) broad at the base, and with razor-sharp edges and tip. They persist 10 to 15 years, and spread all over the tree, but not on the trunk and older branches. Under a systematic point of view, it is related to Araucaria araucana that lives further southwest in South America, differing in the narrower leaves. The main isolated flavonoids belong to the class of the biflavonoids: amentoflavone, monomethylamentoflavone, di-O-methyl amentoflavone, ginkgetin, tri-O-methyl amentoflavone, tetra-O-methyl amentoflavone, that differ by the number and position of the methoxyl group. The biflavonoids found in A. angustifolia act like free radicals scavengers and show an efficient protection against oxidative damage, demonstrating to be an excellent option to the use of antioxidants and photoprotectives [8] [9].

The flavonoids are found in the secondary metabolism of the plants and they are characterized for having antibacterial properties, anticarcinogenic, anti-inflammatory, among others [10]. According to Yamaguchi [8], the flavonoids, not only show antioxidant and antiaging properties, but also protect the skin from the UV solar radiation. Thus, the objective of this work was to characterize and evaluate alcoholic extracts obtained from the pine tree seeds and to explore their possible applications as antioxidant in cosmetic, trying to further valorize, under a functional point of view, this Brazilian plant species with an ancient story of traditional uses [8] [9]. Finally, valorization of local plants through the development of NTFP (non timber forest products) contributes to supporting biodiversity and sustainable use of natural resources.

\section{Materials and Methods}

Seeds from the Araucaria angustifolia were collected in July 2009, in Curitiba/Paraná and delivered to the University of Ferrara/Italy where they were stored at $-20^{\circ} \mathrm{C}$ until the preparation of the extracts. The plant material to be investigated was dried at room temperature and the seeds were separated in pulps (endosperm and embryo) and shells (external teguments). The shells were pulverized in a mill rotor (Variable-Speed Rotor Mill PULVERISETTE 14, Fritsch GmbH, 55743 Idar-Oberstein, Germany), while the pulps were grinded on a hand 
grail. The samples were stored at $4^{\circ} \mathrm{C}$ with controlled humidity. The extracts were prepared macerating $20 \mathrm{~g}$ of the crushed material with $100 \mathrm{ml}$ of methanol for 20 minutes under sonication. The choice of methanol was due, after several attempts, to its polarity and capability of extracting flavonoids and biflavonoids [10]. The material was then filtered in a Büchner filter and evaporated under vacuum; part of the sample was re-suspended at a 10 $\mathrm{mg} / \mathrm{ml}$ concentration in methanol and processed as described below.

\subsection{Quantitative Analysis of the Main Chemical Constituents by HPTLC and Spectrophotometry}

Fifty microliters $(10 \mathrm{mg} / \mathrm{mL}$ ) of each sample extract (pulp and shell) of A. angustifolia were solubilized in methanol and analyzed using High Performance thin layer plates (HPTLC) eluted in two steps with different mobile phases: the first using ethyl acetate, formic acid, acetic acid and water (100:11:11:26 v/v/v/v) to elute total flavonoid, and the second one using chloroform, acetone and formic acid (75:16.5:8.5 v/v/v) for biflavonoid. The plates were then treated with NP/PEG reagent, NP 1.0\% in methanol, followed by a solution of PEG 4000 $5.0 \%$ in ethanol [11]. The quantitative assays were performed in triplicate, and the results were expressed by the average of the data achieved followed by the coefficient of variation. Plants phenolic compounds are classified in many categories, such as simple phenols, phenolic acids, coumarines, flavonoids, stilbenes, condensed and hydrolysable tannins, lignans and lignins [12]. The total polyphenols determination has been accomplished according to the method proposed by Folin and Denis in 1912 and successively modified by Folin and Ciocalteu in 1927. The total phenols were determined at $765 \mathrm{~nm}$ through a calibration curve of gallic acid, being the result expressed in equivalent of gallic acid [13]. The analysis of the total flavonoids was accomplished mixing 1 $\mathrm{mg} / \mathrm{ml}$ of the extract suspension with $1 \mathrm{ml}$ of solution at $2 \%$ of $\mathrm{AlCl}_{3}$ in methanol. The spectrophotometer was previously restarted with methanol and a calibration curve was obtained using hyperoside as reference. After 10 minutes at room temperature, the absorbance of the samples was measured at $394 \mathrm{~nm}$. For the quantitative determination of flavonoids the calibration curve was prepared with a solution of hyperoside (range $0-60 \mu \mathrm{g} / \mathrm{ml}$ and the results were expressed as milligram hyperoside equivalents (HE) per gram of samples, i.e. oils and methanol macerate (mg HE/g). For determination of total proanthocyanidins, the phenolic compounds known also as condensed tannins, the method described by Porter et al. [14] was used. 2.4 of butanol/HCI (95:5 v/v) was added to $1 \mathrm{mg} / \mathrm{ml}$ of extract suspension, plus $80 \mu \mathrm{L}$ of $2 \%$ solution of $\mathrm{NH}_{4} \mathrm{Fe}\left(\mathrm{SO}_{4}\right)_{2}$. The mixture was placed at $95^{\circ} \mathrm{C}$ for 40 minutes. The spectrophotometer (Thermo Spectronic Helios, Cambridge, UK) was previously restarted with methanol to avoid solvent interference. The total proanthocyanidins levels are expressed as cyanidinchloride, therefore, a calibration curve was prepared with an appropriate set of cyanidin chloride concentrations. Absorbance of samples and control was taken at $550 \mathrm{~nm}$ leading to total proanthocyanidins determination in A. angustifolia seed samples extracts.

\subsection{Evaluation of Antioxidant Activity}

\subsubsection{Spectrophotometric Method}

The evaluation was based on the capacity of the A. angustifolia seed extracts to reduce the free radicals ABTS and DPPH, generated in vitro. The inactivation of these free radicals represents the total antioxidant capacity of the extracts [15] [16].

DPPH. The method is based on the reduction of the DPPH radical [17]. The samples were prepared by mixing $100 \mu \mathrm{L}$ of each extract with a methanol solution of DPPH $1 \times 10^{-4} \mathrm{M}$ kept under mixing at a speed of 200 rpm in the dark. The absorbance of the reaction mixture was read in a spectrophotometer (at $517 \mathrm{~nm}$ ) after 30 min incubation. Methanol (1 ml) was used as control. The percentage of free radical scavenging effect [18] was calculated as follows: $\%$ inhibition $=1-\frac{\mathrm{AA}}{\mathrm{AB}} * 100$. where AA represents the absorbance of DPPH with the extracts and $\mathrm{AB}$ represents the absorbance of $\mathrm{DPPH}$ without the extracts; was all the data are expressed as $\mathrm{IC}_{50}$.

ABTS. The ABTS radical was obtained by a $2 \mathrm{mM}$ solution of ABTS $(0.011 \mathrm{~g} / 10 \mathrm{~mL}$ water $)$ keeping the mixture in the dark for 16 hours. Before the analysis the spectrophotometer was set at $734 \mathrm{~nm}$ with a phosphate buffer (PBS) $5 \mathrm{nM}$ at pH 7.4. Different dilutions have been prepared for both extracts in a concentration range of $5-200 \mu \mathrm{L} / \mathrm{mL}$ in methanol. The samples have been prepared by mixing $10 \mu \mathrm{L}$ of each dilution with $990 \mu \mathrm{L}$ of ABTS, while $10 \mu \mathrm{L}$ of methanol sample was used as blank. A measure of the absorbance has been made of each sample 1 min after the addition of the radical. The inhibition percentage of the radical ABTS has been calculated 
with the following equation: $\%$ inhibition $=1-\frac{\mathrm{AA}}{\mathrm{AB}} * 100$. Where $\mathrm{AA}$ is the absorbance of ABTS with the extract and $\mathrm{AB}$ is the absorbance of ABTS without the extract and was expressed as $\mathrm{IC}_{50}$.

\subsubsection{Oxygen Radical Absorbance Capacity Using Fluorescein as a Fluorescent Probe (ORAC-FL)}

The ORAC assay was carried out on a Fluoroskan FL ${ }^{\circledR}$ ascent (Thermo Fisher Scientific, Inc. Waltham, MA, USA) with fluorescent filters (excitation wavelength: $485 \mathrm{~nm}$; emission filter: $538 \mathrm{~nm}$ ), following the procedure by Hong, Guohua \& Ronald properly adapted as reported in a previous work [19]. Briefly, in the final assay mixture $(0.2 \mathrm{~mL}$ total volume), fluorescein sodium salt $(85 \mathrm{nM})$ was used as a target of free radical with 2,2'-azobis (2-amidinopropane) dihydrochloride (AAPH) as a peroxyl radical generator. Trolox ${ }^{\circledR}$, a watersoluble analogue of vitamin E, was used as a standard control: a calibration curve was carried out with 10, 20, 30, 40, $50 \mu \mathrm{M}$ solution. The tested compounds were dissolved in PBS and prepared immediately before the experiments. The fluorescence measurements, carried out at $37^{\circ} \mathrm{C}$, were recorded at 5 min intervals up 30 min after the addition of AAPH. The ORAC values, calculated as difference of the areas under the quenching curves of fluoresceine between the blank and the sample, were expressed as Trolox ${ }^{\circledR}$ equivalents $(\mathrm{TE})(\mu \mathrm{mol} \mathrm{TE} / \mathrm{g}) \mathrm{pH}=$ 7.4. All the experiments were performed in three replicates.

\subsubsection{Photochemiluminescence (PCL)}

In the aim to fully evaluate the antioxidant capacity of the extracts, another experimental protocol, based on photochemiluminescence (PCL) was performed. The method allows evaluating the activity of the extract of $A$. angustifolia through the setting up of a calibration curve with a reference antioxidant, thus expressing the values obtained as $\mu \mathrm{mol}$ of Trolox ${ }^{\circledR}$ per gram of extract. The analysis has been made using Photochem ${ }^{\circledR}$ and following the method described by Lewin and Popov [20] and conducted according to the protocol provided by Analytik Jena, Jena, Germany. The concentration of the added extract solution was such that the generated luminescence during the $180 \mathrm{~s}$ sampling interval fell within the limits of the standard curve. The extracts were centrifuged (5 $\min$ at $16,000 \mathrm{~g}$ ) prior to analysis. The antioxidant assay was carried out in triplicate for each sample, and $20 \mu \mathrm{L}$ of the diluted extract $(1: 40, \mathrm{v} / \mathrm{v})$ in HPLC-grade methanol was sufficient to correspond to the standard curve.

\subsubsection{HPTLC Method Using 2,2'-Azinobis-(3-Ethylbenzothiazoline-6-Sulfonate) (ABTS) Radical Assay, Diphenylpicrylhydrazyl (DPPH) Radical Assay}

To evaluate the antioxidant activity of the compounds that characterizes the extract, rehearsals have been made with the radicals ABTS and DPPH on chromatography plates coated with a high performance silica gel. The objective was to evaluate the capacity of the extract of discoloring the solutions of ABTS and DPPH, which presented, respectively, the colors green and purple. This methodology involves the preparation and the elution of two plates, that are then derivatized, one with a watery solution of ABTS and the other one with an ethanolic solution of DPPH, following properly modified procedures reported by Rossi et al. [13]. The activity of the eluted extract was immediately monitored both after the derivatization and 24 hours, for verifying those bands most involved in antioxidant capacity together with the presence of less abundant biomolecules with slower reactivity and/or with a delayed appearance of stains.

\subsection{Preparation of the Cosmetic Formulations}

The final goal of the investigation was to find application, as antioxidant, of Brazilian Araucaria angustifolia seed extracts - i.e. from external teguments (shell), and from endosperm and embryo (pulp) —in cosmetic products. The target would be that of verifying if the samples derived from the seeds, when incorporated to the formulations, will exert anti-aging and moisturizing properties in view of their antioxidant capacity expressed as crude extracts.

\subsubsection{Composition of the $0 / \mathrm{W}$ Emulsion}

The compounds on phase A (oil phase) and phase B (water phase) have been heated in separated containers, at $70^{\circ} \mathrm{C}$. The oily phase has been incorporated to the watery phase under mechanic agitation and it has been cooled with a cold bath at a temperature below $40^{\circ} \mathrm{C}$, and then, phase $\mathrm{C}$ has been added. At the end, the $\mathrm{pH}$ has been adjusted to 6.0 (Tables $1-3)$. 
Table 1. Composition of the O/W emulsion.

Composition (INCI)

Function

Amount (\%)

Phase A

Glyceryl stearate (and) ceteareth-20 (and) ceteareth-12 (and) ceteayl alcohol (and) cetyl palmitate

Base self emulsifying

8.00

Cetylstearyl alcohol

Emollient/hickener

1.50

Hydrogenated polyisobutene

Emollient/emulsifier

Hydrogenated polydecene

Emollient

Decyl oleate

Emollient

Cyclopentasiloxane

Emollient

Dimethicone

Defoamer/emollient

Phenoxyethanol (and) butylparaben (and) propylparaben (and) isobutylparaben

Preservative

Phase B

Aqua

Vehicle

66.40

Disodium EDTA

Chelating

0.10

Glycerin

Moist

3.00

Phase C

Ethyl alcohol

Denaturant/solvent

10.00

Powder extract of the A. angustifolia

Active principle

1.00

Sodium hydroxide/citric acid

$\mathrm{pH}$ corrector

q.s pH 6

Table 2. Composition of the W/O emulsion.

Composition (INCI)

Function

Quantity (\%)

Phase A

PEG-30 dipolyhydroxysteara

$\begin{array}{lc}\text { Emulsifier } & 1.50 \\ \text { Emollient } & 8.00 \\ \text { Emollient } & 8.00 \\ \text { Emollient } & 2.00\end{array}$

Vehicle

68.50

Aqua

Preservative

0.50

(and) propylparaben (and) isobutylparaben

Viscosity modifier

0.50

Phase C

Ethyl alcohol

Solvent/preservative

10.00

Powder extract of the A. angustifolia

Active principle

1.00 
Table 3. Composition of the nonionic gel.

\begin{tabular}{llc}
\hline \multicolumn{1}{c}{ Composition (INCI) } & Function & Quantity (\%) \\
\hline Phase A & & 84.00 \\
Aqua & Vehicle & 1.00 \\
Hydroxyethylcellulose & Emulsion stabilizer, viscosity controller & 5.00 \\
Pentylene glycol & Antimicrobial, solvent, improves water resistance & 9.00 \\
Phase B & & 1.00 \\
Ethyl alcohol & Denaturant/solvent & Active principle \\
Powder extract of the A. angustifolia & . & \\
\hline
\end{tabular}

\subsubsection{Composition of the $\mathrm{W} / \mathrm{O}$ Emulsion}

The compounds from phase A and phase B have been separately weighted and warmed at $70^{\circ} \mathrm{C}$. Phase $\mathrm{B}$ has been slowly added into A and homogenized by a mixer. The compound has been cooled until it hits $40^{\circ} \mathrm{C}$, and then, phase $\mathrm{C}$ was added. Finally, the final $\mathrm{pH}$ was adjusted to 6.0.

\subsubsection{Composition of the Nonionic Gel}

The water has been heated at $60^{\circ} \mathrm{C}$, hydroxyethylcellulose and the pentylene glycol were added under mixing. Phase B was added over phase A. The $\mathrm{pH}$ was checked and corrected until approximately 5.5 - 6.

\subsection{Evaluation of the Antioxidant Activity of the Finished Cosmetic Formulations}

After the preparation of the three cosmetic formulations, the evaluation of the antioxidant activity of these final compositions was conducted as previously described by PCL in Section 2.2.3 [21]. The analysis has been made to compare the three different formulations with the cosmetic bases and, then, establish which one has the highest antioxidant power. For the analysis of the emulsion bases, both $\mathrm{O} / \mathrm{W}$ and $\mathrm{W} / \mathrm{O}$, a quantity of sample of about $370 \mathrm{mg}$ has been accurately weighted, dissolved in $10 \mathrm{~mL}$ of a mixture of ethanol/ether/hexane $(1: 1: 1 \mathrm{v} / \mathrm{v} / \mathrm{v})$, and it has been sonicated for 20 seconds at $60 \%$ and centrifuged for 10 seconds. For the analysis, $300 \mu \mathrm{L}$ of both mixtures have been used. For the cosmetic formulations with the Araucaria angustifolia extracts, about $200 \mathrm{mg}$ of product has been accurately weighted, dissolved in $10 \mathrm{~mL}$ of the same previous mixture, treated with ultrasounds during 20 seconds and centrifuged for 10 seconds. An amount of $25 \mu \mathrm{L}$ of each sample was used for analysis.

\section{Results and Discussions}

Seeds of Brazilian Araucaria angustifolia were processed to obtain fresh plant material, $55.33 \mathrm{~g}$ of shell and $122.77 \mathrm{~g}$ of pulp, were extracted by ultrasound-assisted maceration. The dry weighted extraction yields were $1.7044 \mathrm{~g}$ for the shell and $0.9818 \mathrm{~g}$ for pulp samples, corresponding to $8.5 \%$ and $4.91 \%$, respectively.

\subsection{Qualitative Analysis of the Main Chemical Constituents by HPTLC}

At first a preliminary qualitative evaluation of the methanol extracts (pulp and shell), was lead by chromatography on high performance silica gel thin layer (HPTLC), the plates were sprayed with NP/PEG reagent (diphenylboryloxyethylamine $1.0 \%$ in methanol, followed by a solution of polyethylene glycol 4000 (5.0\% in ethanol) and the orange stain revealed the presence of flavonoids (polyphenols compounds, and proanthocyanidins). This result supported the continuation of the studies (Figure 1 and Figure 2).

\subsection{Quantitative Determination of the Active Principles}

The quantitative data were obtained coupling HPTLC and spectrophotometric evidences (see Section 2.1), the amounts of flavonoids resulted visibly higher in the methanol extract of the shell, Figure 3, of A. angustifolia than in those of the pulp, Figure 4 and Figure 5. 


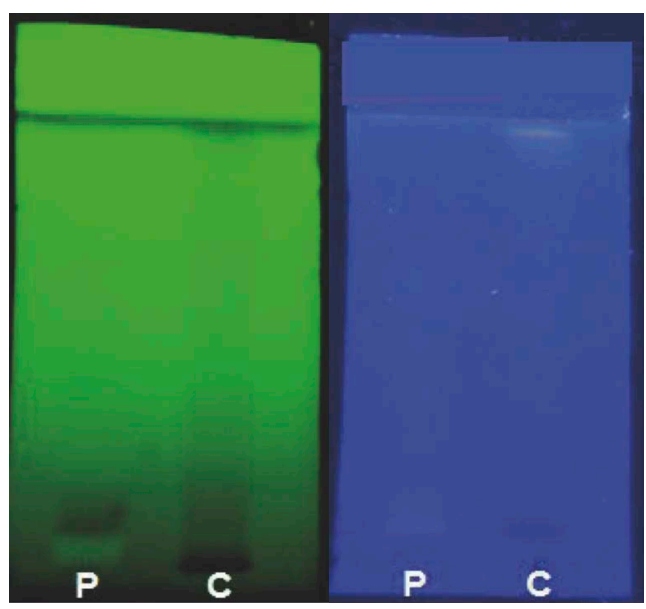

Figure 1. CCD plates sprayed by NP/PEG 400 and visualized under ultraviolet light, first at $\lambda$ $=254 \mathrm{~nm}$ and after at $\lambda=366 \mathrm{~nm}$. P: methanolic extract of the pulp shell of the A. angustifolia . Mobile phase: ethyl acetate/formic acid/acetic acid/water (100:11:11:26 v/v/v/v).

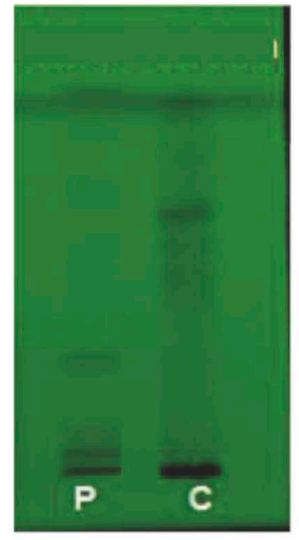

1 - before - $254 \mathrm{~nm}$

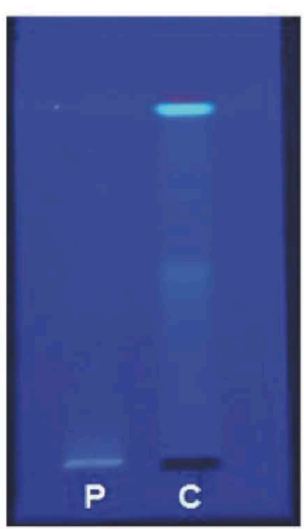

2 - before - $366 \mathrm{~nm}$

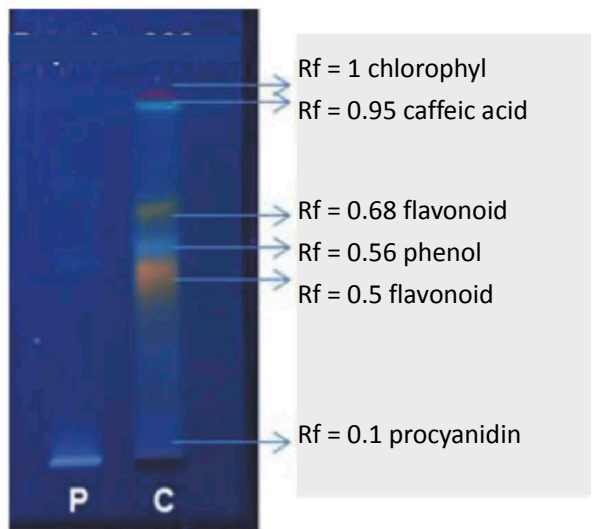

3 - after $-366 \mathrm{~nm}$

Figure 2. CCD plates sprayed with NP/PEG 400 and visualized under ultraviolet light, initially (1) in $\lambda=254 \mathrm{~nm}$, lately (2) at $\lambda=366$, and after 24 hours. P: methanolic extract of the pulp of A. angustifolia; C: methanolic extract of the shell of $A$. angustifolia. Mobile phase: chloroform/acetone/formic acid (75:16.5:8.5 v/v/v).

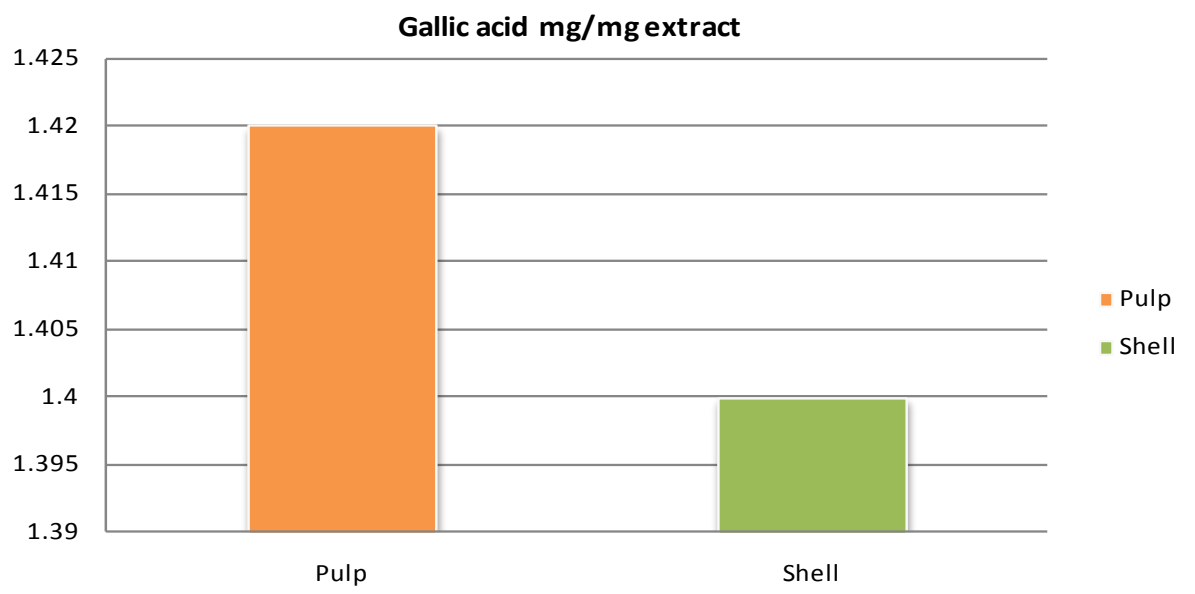

Figure 3. The total polyphenols expressed in mg gallic acid/mg extract, of the methanolic extract of the pulp and shell of $A$. angustifolia. 
Hyperoside $\mathrm{mg} / \mathrm{mg}$ extract

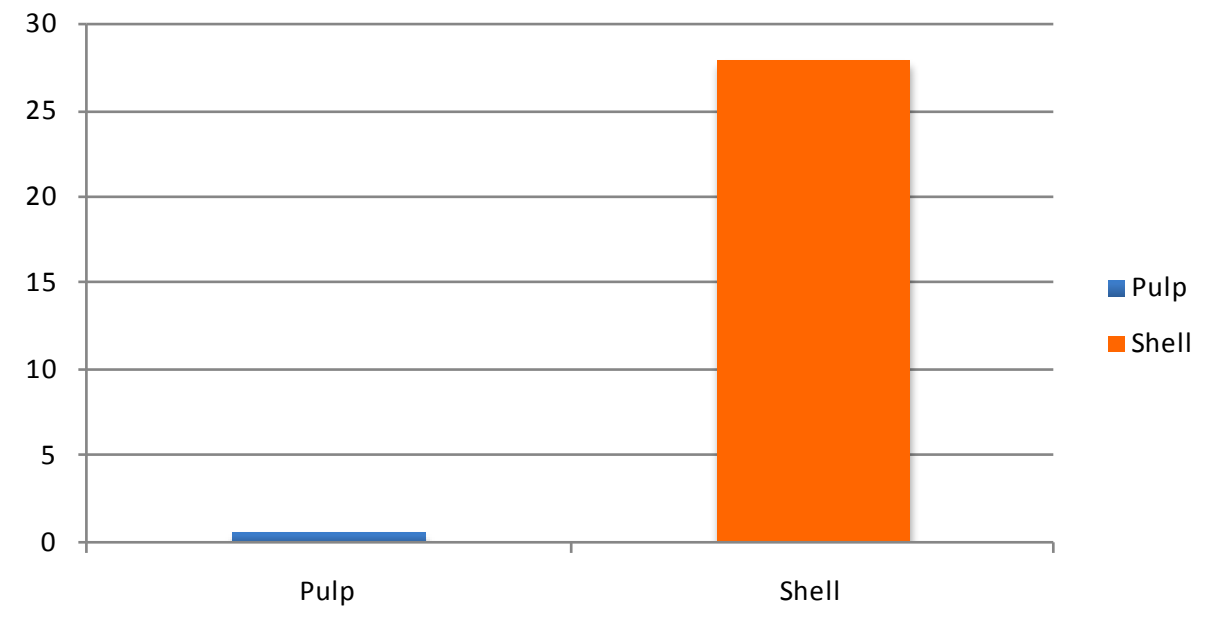

Figure 4. The total flavonoids values expressed in mg hyperoside/mg, pulp and shell of $A$. angustifolia.

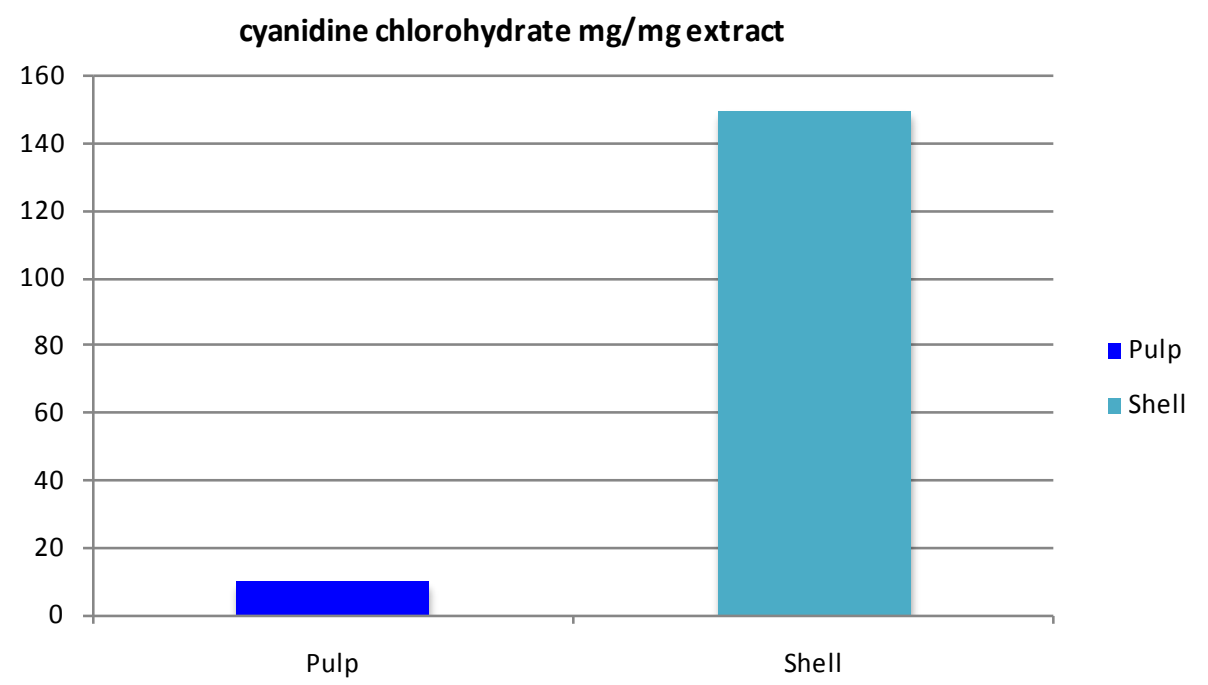

Figure 5. The total proanthocyanidins values expressed in mg cyaniding chloride/mg extract, methanolic extract of the pulp and shell of $A$. angustifolia.

In general, the plant secondary metabolites content in seeds parts is a debated argument since the related literature reports different evidences with regard to the many species and the different compounds investigated for their occurrence in embryos, endosperm and teguments [21] ecotypes [22]. However, for what concerns in particular phenolic and polyphenol compounds, they are often detected in the highest amounts in the seed teguments as confirmed by the data here achieved for $A$. angustifolia. Their occurrence in the external part of the seeds supports the general opinion that phenols and polyphenols have a key role in defense mechanisms in plants. Moreover, phenols and polyphenols in teguments give often rise to seed coat color which is reputed an important aspect for dissemination of the plant species [23]. Since these polyphenols are however known to have also important health benefits for humans (for e.g. antioxidant capacities) the seed teguments-often rejected as waste plant material in agro-food industrial processing - could instead represent an important renewable source of these compounds with important applications, as for e.g. as cosmetic ingredients. In light of these considerations, the results achieved about quantitative determination of polyphenols compounds, flavonoids, proanthocyanidinsin Araucaria angustifoliaseed teguments support the above stated use. In a world economy in which the role of wastes achieve more and more importance in designing food processing of natural raw materials, these results further confirm the added value of sustainable development approaches. 


\subsection{Antioxidant Activity on HPTLC Using Radicals 2,2'-Azinobis (ABTS) and 2,2-Diphnyl-1-Pycril-Hydrazile (DPPH)}

The pictures show the antioxidant activity, displayed by the bands, which corresponds to the main compounds of the seeds extracts, expressed by HP-TLC-bio-autography, using DPPH and ABTS as testing radicals [15]. It resulted clearly evident the most interesting efficacy of the eluted shell extract with both the assays, where a diffused discoloration along all the eluted bands is representative of the antioxidant capacity of the different phenolic compounds (flavonoids, phenols, procyanidins). Only a weak activity has been displayed by pulp extracts probably due to the capacity of the detected procyanidins to reduce ABTS radical. After 24 hours, no other reducing reactions were detected on plated through discoloring bands, indicating that there are no other substances with antioxidant activity against DPPH and ABTS. Moreover, these results are also self-explaining the long capacity of the compounds in neutralizing the oxidant agent.

\subsection{Antioxidant Activity by Spectrophotometric Method}

Through linear regression analysis between the oxidation inhibition percentage and the sample concentration, different equations and angular coefficients have been obtained for each extract and for the standard substance (Trolox ${ }^{\circledR}$ ), allowing to calculate the concentration in $\mu \mathrm{g} / \mathrm{mL}$ necessary to inhibit the radical oxidation $50 \%$ $\left(\mathrm{IC}_{50}\right)$, where low values of $\mathrm{IC}_{50}$ correspond to a high antioxidant activity [24]. Therefore, from these data, see Figure 7, it is evident that both analyzed samples exhibit a higher antioxidant activity than the potent Trolox ${ }^{\circledR}$ used as positive control with a slightly prevalent efficacy of the shell extract than that of pulp (Figure 6).

\subsection{Antioxidant Activity by ORAC-FL Method}

The ORAC method was used to evaluate the antioxidant activity of the extracts against the free radicals generated by AAPH. The methanol extract from the pulp showed $332.6 \pm 25.6 \mu \mathrm{mol} \mathrm{TE} / \mathrm{g}$, while the methanol extract from the shell was $2197.9 \pm 169 \mu \mathrm{mol} \mathrm{TE} / \mathrm{g}$; indicating a much better antioxidant activity in the extract from the shell of $A$. angustifolia confirming the evidences acquired with the previous strategies.

\subsection{Antioxidant Activity by PCL Method}

This method has been used for evaluating the antioxidant capacity of the extracts and cosmetic formulations including them. The methanol extract from the pulp was $90.6 \pm 2.0 \mu \mathrm{mol} \mathrm{T} / \mathrm{g}$, while the one from the shell was $1569.8 \pm 47.3 \mu \mathrm{mol} \mathrm{T} / \mathrm{g}$. Also through this instrumental procedure, the antioxidant capacity of both the extracts from seeds of Brazilian A. angustifolia resulted different with a more interesting efficacy of those from shell than that from pulp.

There is no universal system able to provide information about the "real" antioxidant capacity of a molecule or a mixture. Each method is descriptive of a particular limited behavior, thus a panel of methods, with complementary mechanism is needed. A comparative evaluation of antioxidant efficacy is difficult to perform because the activity depends on the substrate, the reaction medium, the oxidation conditions, interfacial phenomena and
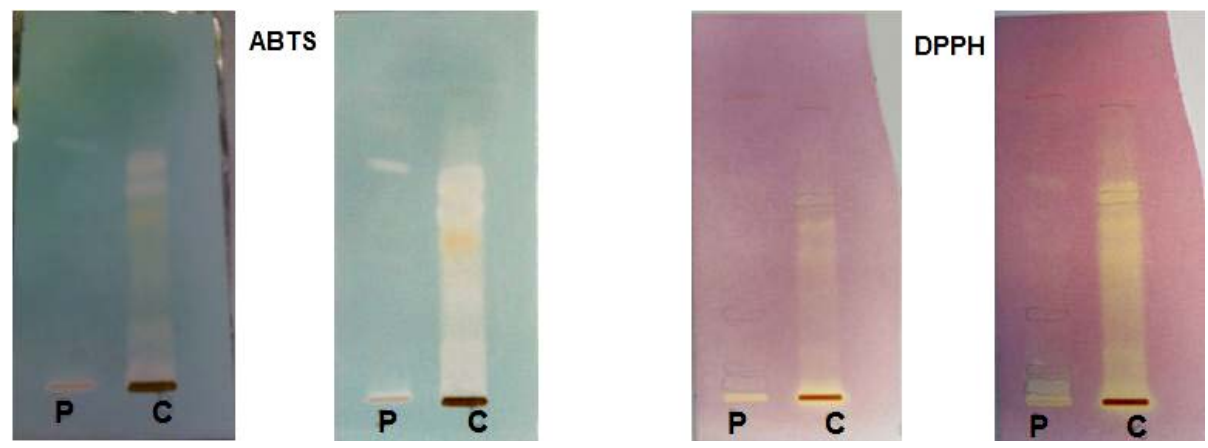

Figure 6. Antioxidant activity revealed with the radical, respectively, ABTS and DPPH, right after their addition and 24 hours later. P: methanolic extract from the pulp of A. angustifolia; C: methanolic extract from the shell of A. angustifolia. 
the antioxidant partitioning properties between phases [25]. Two main mechanism are believed involved in antioxidant capacity assays:

The first is an "assessment of antioxidant efficacy in relation to free radical species". This category includes different reaction mechanisms models such as:

1) Hydrogen atoms transfer reactions model (HAT) based on the transfer of hydrogen atoms;

2) Single electron transfer reactions model (SET) based on the transfer of a single electron;

3) Hydrogen-electron transfer reactions model combining the two mechanisms HAT and SET.

This category is useful to describe the properties of a molecule or raw material.

The second category is an "assessment of antioxidant efficacy using biological significant markers and significant substrates". This category involves the determination of antioxidant efficacy via evaluation of the protection against damaging effects on a biological substrate, produced by reactive species of oxygen (ROS) or related nitrogen oxide species (RNOS). Typically, when reacting with lipids, lipoproteins, DNA etc.

In this work we have taken into consideration models based on the first mechanisms. The HAT reaction, i.e. ORAC, is a key step promoting radical chain reactions and thus measure the capacity of inhibits propagation of oxidation (i.e. oxidation of fats). Among models based on SET mechanisms, we have selected ABTS, PCL and DPPH. SET based assays are useful to assess the capability of an antioxidant to reduce a specific oxidant. About the most well known ORAC and DPPH assays it must be underlined that they are not strictly related to a compound's efficacy against ROS and consequently not strictly related to the antioxidant activity, but rather to describe the property of a raw material (molecule, food, etc.). On the other hand, PCL and ABTS are more suited to evaluate the capability of an ingredient or mixture to be effective against an oxidative stressor.

\subsection{Evaluation of the Antioxidant Activity of Cosmetic Formulations}

Previous studies conduced by us have demonstrated [26] that the type of formulation, i.e., $\mathrm{W} / \mathrm{O}, \mathrm{O} / \mathrm{W}, \mathrm{W} / \mathrm{O} / \mathrm{W}$, gel, etc., the final $\mathrm{pH}$ or storage conditions and the cosmetic base could influence the expression of a functional ingredient's antioxidant capacity. Therefore, in case of ingredients claimed for antioxidant activity, we believe necessary to evaluate, at least, the real ability, in relation with the other ingredients and excipients, to confer antioxidant capacity to the finished formulation. Therefore, three different cosmetic formulations were prepared using the shell extracts. The antioxidant capacity was then checked and compared with the corresponding cosmetic bases as the reference sample. As demonstrated by our previous study, the PCL method can provide evaluation of the cosmetic formula as well as the raw ingredients thus consenting effective comparison. As expected, all bases displayed a much lower potency as compared to those containing A. angustifolia extracts. Furthermore, the formulation W/O and gel showed the higher antioxidant activity $(4.41 \pm 0.07 \mu \mathrm{mol} \mathrm{T} / \mathrm{g}$ and $4.0 \pm 0.07 \mu \mathrm{mol}$ $\mathrm{T} / \mathrm{g}$ ) followed by O/W emulsion (3.5941 $\pm 0.172 \mu \mathrm{mol} \mathrm{T} / \mathrm{g}$ ), as shown in the graphics (Figure 7, Figure 8). Such potencies are compatible with a potential efficacy on skin.

\section{Conclusion}

The determination of polyphenols compounds, flavonoids, proanthocyanidins content in A. angustifolia seed parts pointed out their highest abundance in the teguments. In any case, the quantitative determination in the $A$. angustifolia seed teguments of these important antioxidants supports the possible use of these plant materials as renewable source of active molecules for cosmetic products. In fact, the methanolic extracts obtained from the shell (external teguments) and pulp (endosperm and embryo) of Brazilian Araucaria angustifolia seeds have both shown the presence of molecules that have the capacity of trapping free radicals (for e.g. polyphenols compounds, flavonoids, proanthocyanidins). The overall antioxidant capacity of the shell extracts resulted always higher than that of the pulp with all the assays performed, i.e. DPPH, ABTS, ORAC, and the higher values were even better than the Trolox ${ }^{\circledR}$ (synthetic vitamin $E$ analog used as reference), suggesting an interesting applicative perspective in cosmetic and nutritional fields, where the search for natural antioxidant has been increasing in the last few years. In the light of these results, the potential cosmetic application was explored through the incorporation of the methanolic extract from the shell in three different cosmetic formulations (gel, $\mathrm{O} / \mathrm{W}, \mathrm{W} / \mathrm{O}$ ). The data collected strongly support the suggestion to valorize the Brazilian A. angustifolia seeds - shell in particular-as source of antioxidant biomolecules for formulation of antiaging cosmetic products. Further studies are currently ongoing in order to confirm antioxidant activity on volunteers. 


\section{$1 \mathrm{C50} \mathrm{mg} / \mathrm{ml}$}

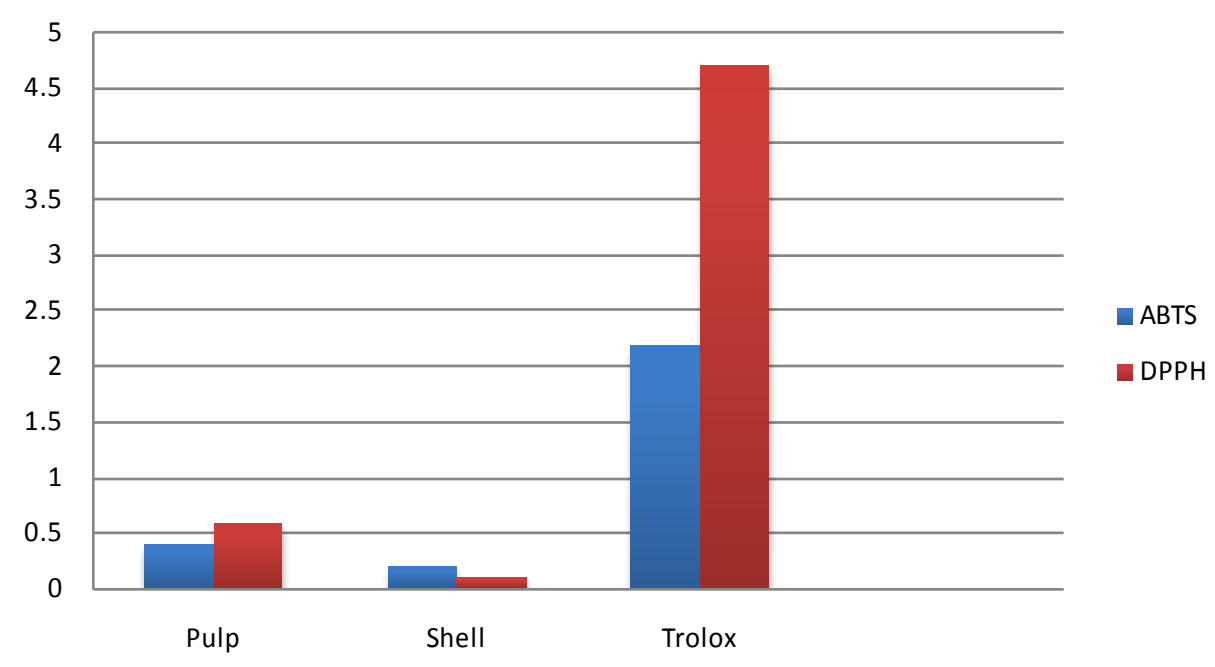

Figure 7. Antioxidant activity, expressed as IC50 of the extracts, evaluated by the DPPH and ABTS methods, compared to the standard substance (Trolox ${ }^{\circledR}$ ).

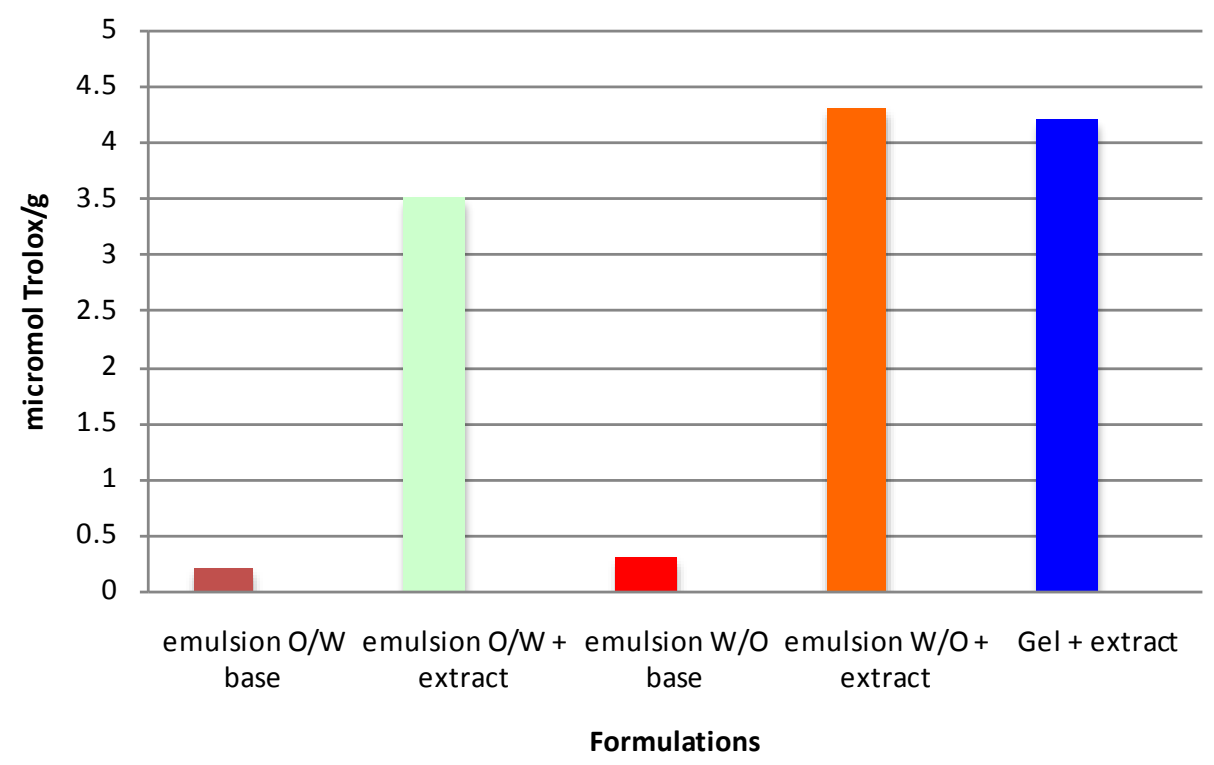

Figure 8. Antioxidant activity of cosmetic formulations containing the methanolic extract from the shell, compared the base formulations, expressed in $\mu \mathrm{mol}$ Trolox/g.

\section{Acknowledgements}

We thank the Ministry of Education and Research (PRIN, Grant 20105YY2HL_006) and Ambrosialab for financial support. Prof. Gianfranco Franz, International Master Course Eco-polis, for the kind full collaboration in Curitiba. Elisa Durini, Alberto Casolari and Immacolata Maresca are gratefully acknowledged for technical assistance.

\section{References}

[1] Atoui, A.K., Mansouri, A., Boskou, G. and Kefalas, P. (2005) Tea and Herbal Infusions: Their Antioxidant Activity and Phenolic Profile. Food Chemistry, 89, 27-36. http://dx.doi.org/10.1016/j.foodchem.2004.01.075

[2] Barreiros, A.L.B.S., David, J.M. and David, J.P. (2006) Estresseoxidativo: Relação entre geração de espéciesreativas e defesa do organism. Química Nova, 29, 113-123. http://dx.doi.org/10.1590/S0100-40422006000100021 
[3] Halliwell, B. (1994) Free Radicals and Antioxidants: A Personal View. Nutrition Reviews, 52, 253-265. http://dx.doi.org/10.1111/j.1753-4887.1994.tb01453.x

[4] Pompella, A. (1997) Biochemistry and Histochemistry of Oxidant Stress and Lipid Peroxidation. International Journal of Vitamin and Nutrition Research, 67, 289-297.

[5] Magalhães, J. (2000) O uso de cosméticosatravés dos tempos, envelhecimentocutâneo. In: Rubio, Ed., Cosmetologia: Com questões de avaliação, Rio de Janeiro, 33-42.

[6] F'Guyer, S., Afaq, F. and Mukhtar, H. (2003) Photochemoprevention of Skin Cancer by Botanical Agents. Photodermatology, Photoimmunology \& Photomedicine, 19, 56-72. http://dx.doi.org/10.1034/j.1600-0781.2003.00019.x

[7] Nikolic, K.M. (2006) Theoretical Study of Phenolic Antioxidants Properties in Reaction with Oxygen-Centered Radicals. Journal of Molecular Structure: THEOCHEM, 774, 95-105. http://dx.doi.org/10.1016/j.theochem.2006.07.017

[8] Yamaguchi, L.F., Vassão, D.G., Kato, M.J. and Mascio, P. (2005) Biflavonoids from Brazilian Pine Araucaria angustifolia as Potentials Protective Agents against DNA Damage and Lipoperoxidation. Phytochemistry, 66, 2238-2247. http://dx.doi.org/10.1016/j.phytochem.2004.11.014

[9] Michelon, F., Branco, C.S., Calloni, C., Giazzon, I., Agostini, F., Spada, P.K.W. and Salvador, M. (2012) Araucaria angustifolia: A Potential Nutraceutical with Antioxidant and Antimutagenic Activities. Current Nutrition \& Food Science, 8, 155-159. http://dx.doi.org/10.2174/157340112802651103

[10] Middleton, E. and Kandaswami, C. (1986) The Impact of Plant Flavonoids on Mammalian Biology: Implications for Immunity, Inflammation and Cancer. In: Harbone, J.B., Ed., The Flavonoids: Advances in Research since 1986, Chapman \& Hall, London, 619-652.

[11] Wagner, H. and Bladt, S. (2001) Plant Drugs Analisis, a Thin Layer Chromatography. 2nd Edition, Springer-Verlag Berlin, Heidelberg, New York.

[12] Shahidi, F. and Nazck, M. (2004) Extration and Analysis of Phenolics in Food Review. Journal of Chromatography A, 1054, 95-111. http://dx.doi.org/10.1016/j.chroma.2004.08.059

[13] Singleton, V.L. and Rossi, J.A. (1965) Colorimetry of Total Phenolics with Phosphomolibdic-Phosphotungstic Acid Reagent. American Journal of Enology and Viticulture, 16, 144-158.

[14] Porter, L.J., Hrstich, L.N. and Chan, B.C. (1985) The Conversion of Procyanidis and Prodelphinidins to Cyanidin and Delphinine. Phytochemistry, 25, 223-230. http://dx.doi.org/10.1016/S0031-9422(00)94533-3

[15] Prior, R.L., Wu, X. and Schaich, K. (2005) Standardized Methods for the Determination of Antioxidant Capacity and Phenolics in Food and Dietary Supplements. Journal of Agricultural and Food Chemistry, 53, 4290-4302. http://dx.doi.org/10.1021/jf0502698

[16] Butera, D., Tesoriere, L., Di Gaudio, F., Bongiorno, A., Allegra, M., Pintaudi, A.M., Kohen, R. and Livrea, M.A. (2002) Antioxidant Activities of Sicilian Prickly Pear (Opuntiaficusindica) Fruit Extracts and Reducing Properties of Its Betalains: Betanin and Indicaxanthin. Journal of Agricultural and Food Chemistry, 50, 6895-6901. http://dx.doi.org/10.1021/jf025696p

[17] Wang, M., Rangarajan, M., Shao, Y., La Voie, E.J., Huang, T.C. and Ho, C.T. (1998) Antioxidative Phenolic Compounds from Sage (Salvia officinalis). Journal of Agriculture and Food Chemistry, 46, 4869-4873. http://dx.doi.org/10.1021/jf980614b

[18] Moure, A., Franco, D., Sineiro, J., Dominguez, H., Núñez, M.J. and Lema, J.M. (2000) Evaluation of Extracts from Gevuinaavellana Hulls as Antioxidants. Journal of Agriculture and Food Chemistry, 48, 3890-3897. http://dx.doi.org/10.1021/jf000048w

[19] Baldisserotto, A., Malisardi, G., Scalambra, E., Andreotti, E., Romagnoli, C., Vicentini, C.B., Manfredini, S. and Vertuani, S. (2012) Synthesis, Antioxidant and Antimicrobial Activity of a New Phloridzin Derivative for Dermo-Cosmetic Applications. Molecules, 17, 13275-13289. http://dx.doi.org/10.3390/molecules171113275

[20] Lewin, G. and Popov, I. (1994) Photochemiluminescent Detection of Antiradical Activity III: A Simple Assay of Ascorbate in Blood Plasma. Journal of Biochemical and Biophysical Methods, 28, 277-282. http://dx.doi.org/10.1016/0165-022X(94)90003-5

[21] Giovanni, D., Bonetti, A., Minelli, M., Marotti, I., Catizone, P. and Mazzanti, A. (2006) Content of Flavonols in Italian Bean (Phaseolus vulgaris L.). Food Chemistry, 99, 105-114. http://dx.doi.org/10.1016/j.foodchem.2005.07.028

[22] Bruni, R., Medici, A., Guerrini, A., Scalia, S., Poli, F., Romagnoli, C., Muzzoli, M. and Sacchetti, G. (2002) Tocopherol, Fatty Acids and Sterol Distributions in Wild Ecuadorian Theobroma subincanum (Sterculiaceae) Seeds. Food Chemistry, 77, 337-341. http://dx.doi.org/10.1016/S0308-8146(01)00357-0

[23] Loginov, M., Boussetta, N., Lebovka, N. and Vorobiev, E. (2013) Separation of Polyphenols and Proteins from Flaxseed Hull Extracts by Coagulation and Ultrafiltration. Journal of Membrane Science, 442, 177-186. http://dx.doi.org/10.1016/j.memsci.2013.04.036 
[24] Stocks, J., Gutteridge, J.M.C., Sharp, R.J. and Dormandy, T.L. (1974) The Inhibition of Lipid Autoxidation by Human Serum and Its Relationship to Serum Proteins and Crtocopherol. Clinical Science \& Molecular Medicine, 47, $223-233$.

[25] Litescu, S.C., Eremia, S. and Radu, G.L. (2010) Methods for the Determination of Antioxidant Capacity in Food and Raw Materials. Advances in Experimental Medicine and Biology, 698, 241-249. http://dx.doi.org/10.1007/978-1-4419-7347-4_18

[26] Ziosi, P., Manfredini, S., Vertuani, S., Ruscetta, V., Sacchetti, G., Radice, M. and Bruni, R. (2010) Evaluating Essential Oils in Cosmetics: Antioxidant Capacity and Functionality. Cosmetic \& Toiletries, 125, 6. 